\title{
The latissimus dorsi flap continues to play an important role in cardiothoracic surgery
}

\author{
Afshin Ehsan, MD, and Thomas Ng, MD \\ From the Division of Cardiothoracic Surgery, The Warren Alpert Medical School of Brown University, \\ Providence, RI. \\ Disclosures: Authors have nothing to disclose with regard to commercial support. \\ Received for publication June 30, 2016; accepted for publication July 1, 2016; available ahead of print July 30 , \\ 2016. \\ Address for reprints: Thomas Ng, MD, 2 Dudley St, Ste 470, Providence, RI 02905 (E-mail: tng @usasurg.org). \\ J Thorac Cardiovasc Surg 2016;152:1452-3 \\ $0022-5223 / \$ 36.00$ \\ Copyright $\odot 2016$ by The American Association for Thoracic Surgery \\ http://dx.doi.org/10.1016/j.jtcvs.2016.07.015
}

Although the incidence of infection after pacemaker or implantable cardioverter-defibrillator placement is low, with the increasing number of patients receiving these cardiovascular implantable electronic devices (CIEDs), cardiothoracic surgeons will increasingly be faced with managing device infections. ${ }^{1,2}$ Guidelines from the American Heart Association ${ }^{1}$ and from the working collaborative of the British Society for Antimicrobial Chemotherapy, British Heart Rhythm Society, British Cardiovascular Society, British Heart Valve Society, and British Society for Echocardiography ${ }^{2}$ recommend device removal as the optimal treatment of an infected CIED. However, this is not without risk, may not always be possible by percutaneous methods, and requires careful planning. The timing and location of a new CIED may be problematic in patients who are pacemaker-dependent or with difficult venous access. ${ }^{1,2}$ Kim and colleagues ${ }^{3}$ report the successful salvage of an infected CIED with the use of a latissimus dorsi myocutaneous flap, thus avoiding the need for device removal.

In this report by Kim and colleagues, ${ }^{3} 5$ consecutive patients with an exposed CIED were treated; 2 had prior failed local flap procedures. All patients underwent wide debridement of the infected pocket, followed by reconstruction of the defect and coverage of the CIED with a pedicled latissimus dorsi myocutaneous flap. After $>$ 1 year of follow-up, the authors salvaged all CIEDs, and no patient experienced recurrent device infection. A video, available online or by request to the authors, illustrates their technique.

This study by Kim and colleagues ${ }^{3}$ has several limitations. First, the number of patients evaluated was small; therefore, more studies with larger numbers are needed to confirm the results. Second, the study population was confined to patients presenting with an exposed CIED but without active infection as manifested by persistent bacteremia, fever, or leukocytosis. Although the American Heart Association $^{1}$ and the collaborative of several United Kingdom societies ${ }^{2}$ consider any exposed CIED as infected,

\section{References}

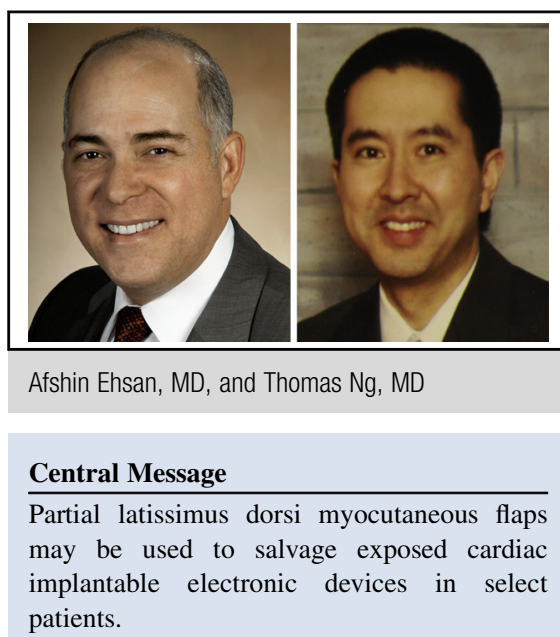

See Article page 1450.

the 5 patients treated by Kim and colleagues ${ }^{3}$ clearly represent the lower end of the severity spectrum compared with active infection of the generator, leads, or native cardiac structures. Therefore readers should not mistakenly conclude that this muscle flap treatment will also be effective in patients with active CIED infection.

National guidelines recommend removal of an exposed CIED $^{1,2}$; however, there are circumstances when removal may be less desirable. The report by Kim and colleagues ${ }^{3}$ provides cardiothoracic surgeons with another option to treat an exposed CIED, without the need for device removal. The latissimus dorsi flap has long been important in the management of complex intrathoracic or chest wall problems such as airway fistulas, esophageal fistulas, empyemas, and chest wall reconstruction after resection for neoplasm, infection, or radiation necrosis. ${ }^{4-6}$ Its volume, length of reach, and ability to carry skin and subcutaneous tissue make it among the most dependable flaps for thoracic reconstruction. In this report, the latissimus dorsi muscle continues to prove its value in cardiothoracic surgery, with the authors utilizing this versatile flap in a novel approach toward salvaging an exposed CIED.

1. Baddour LM, Epstein AE, Erickson CC, Knight BP, Levison ME, Lockhart PB, et al. Update on cardiovascular implantable electronic device infections and their management: a scientific statement from the American Heart Association. Circulation. 2010;121:458-77

2. Sandoe JA, Barlow G, Chambers JB, Gammage M, Guleri A, Howard P, et al Guidelines for the diagnosis, prevention and management of implantable cardiac electronic device infection. Report of a joint Working Party project on behalf of the 
British Society for Antimicrobial Chemotherapy (BSAC, host organization), British Heart Rhythm Society (BHRS), British Cardiovascular Society (BCS), British Heart Valve Society (BHVS) and British Society for Echocardiography (BSE). J Antimicrob Chemother. 2015;70:325-59.

3. Kim SW, Thorat TS, Kim JT, Kim YH. Delayed management of exposed pacemaker with partial latissimus dorsi myocutaneous flaps. J Thorac Cardiovasc Surg. 2016;152:1450-1.
4. Arnold PG, Pairolero PC. Chest-wall reconstruction: an account of 500 consecutive patients. Plast Reconstr Surg. 1996;98:804-10.

5. Mansour KA, Thourani VH, Losken A, Reeves JG, Miller JI Jr, Carlson GW, et al Chest wall resections and reconstruction: a 25-year experience. Ann Thorac Surg. 2002; 73:1720-5.

6. Arnold PG, Pairolero PC. Intrathoracic muscle flaps: a 10-year experience in the management of life-threatening infections. Plast Reconstr Surg. 1989;84:92-8. 